\title{
FEMTOSECOND LASER PROCESSING - A NEW ENABLING TECHNOLOGY
}

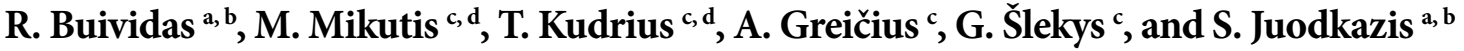 \\ ${ }^{a}$ Centre for Micro-Photonics, Faculty of Engineering and Industrial Sciences, Swinburne University of Technology, \\ Hawthorn, VIC 3122, Australia \\ E-mail: rbuividas@swin.edu.au \\ ${ }^{\mathrm{b}}$ Melbourne Centre for Nanofabrication, 151 Wellington Road, Clayton, VIC 3168, Australia \\ ' Altechna Co. Ltd. Konstitucijos 23C-604, LT-08105, Vilnius, Lithuania \\ ${ }^{\mathrm{d}}$ Laser Research Centre, Vilnius University, Sauletekio 10, LT-10223 Vilnius, Lithuania
}

Received 26 October 2012; accepted 20 December 2012

\begin{abstract}
Recent results in high-precision surface ablation, film removal, ripple formation are presented. Volume processing via polymerization, marking, dicing, cutting, and drilling of semiconductor and dielectric materials are discussed. We focus on processes which can be carried out at a high throughput in the industrial environment or/and can deliver functionalities currently not amenable by competing technologies. Unique features of direct laser writing by femtosecond laser pulses are highlighted. Methodology for solutions of engineering tasks is presented. Namely, the laser irradiation parameters are selected on the basis of the required processing conditions for the material of a workpiece.
\end{abstract}

Keywords: solar cells, micro-optical elements, ripples, 3D polymerisation

PACS: $81.16 .-\mathrm{c}$

\section{Introduction}

Humankind evolution can be presented in steps of material processing technologies starting from the use of stone, iron, bronze in pre-historic times. Technology evolves via active search for more efficient methods of material processing. Just the very definition of the efficiency underpins the importance of short processing time. No surprise that ultra-short, femtosecond ( $1 \mathrm{fs}=10^{-15} \mathrm{~s}$ ) laser pulses are winning greater share in material processing industries. The key unique feature of fs-laser pulses is a possibility to deliver energy in a controlled manner during a sub-1 ps time window - pulse duration - before any material response and modification starts, i. e. before the workpiece "knows" it is processed [1, 2]. Modifications of material evolve over lengthy ps to $\mu \mathrm{s}$ time scales, however, the exact and unperturbed energy delivery is accomplished by energy deposi- tion to an electronic sub-system of material. In this particular feature, there is no any other matching practical technology for the utmost precise and efficient energy delivery [3]. This is why fs-laser processing is an expected winner in the industrial application race. There is one more aspect to this claim. The laser emitting diodes (LEDs) which are used to pump the lasing solid state materiall are very efficient electricity-to-light $(>90 \%)$ energy converters contributing to an overall competitiveness of laser processing. The efficiency of energy conversion in internal combustion engine based technologies with the thermodynamic limit of a Carnot cycle at $\sim 37 \%$ is usually $10 \%$ lower in practical implementation and even fuel cells with practical efficiency of $60 \%$ are inferior to the electricity-to-light conversion in solid state lighting sources used in lasers.

All the material modifications occurring in the workpiece material are in fact taking place in the 
ion/atom sub-system and is the result of the initial excitation and energy absorption/delivery by a sub-1 ps laser pulse. Obviously, by resorting on a multi-pulse excitation and known pathways of energy relaxation in the material, the expected material modification can be controlled and guided via light delivery: pulse repetition rate synchronization with the scanning speed, polarisation, spatial and temporal chirp of the pulses, spatio-temporal focusing, etc.

Here, we present some illustrative examples where fs-laser processing is expected to find practical use on industrial scale. We also outline a strategy how to decide which laser is required (average power, repetition rate, single pulse energy) for the specific fabrication outcome. We show the importance of methodology when material properties and required conditions at the processing location determine the choice of irradiation and laser parameters.

\section{Experiment: requirements for laser}

Laser processing of materials is, first of all, energy delivery to the irradiation location. In some of applications we need high energy absorption in the region initially transparent at the wavelength of exposure, or sometimes we need a high laser repetition to keep constant thermal and ionisation conditions on the surface or in the bulk of the workpiece. Typical tasks where the latter is required would be laser plasma deposition of films by thermally uniform ablation/vaporisation, waveguide writing inside glasses and ceramic materials, or polymerisation of 3D structures. For the initiation of absorption in the otherwise transparent medium it is necessary to reach the optical breakdown or to create conditions very close to it when electronic excitation is already considerable and provides efficient absorption due to free carriers.

The requirements for the laser repetition rate $f[\mathrm{~Hz}]$ are determined by the focal spot diameter $d$, material thermal conductivity (linked to the temperature diffusivity $\left.D\left[\mathrm{~m}^{2} / \mathrm{s}\right]\right)$, and the scanning speed $v(\mathrm{~m} / \mathrm{s})$. In order to keep the constant temperature at the spot of modification the cooling time of the focal spot, $t_{\mathfrak{c}}$, should be larger than the duration between the adjacent fs-pulses, $1 / f[s]$ : $t_{c} \geq 1 / f$. The cooling time of micrometre-sized vol- umes in the case of tightly focused laser pulses $t_{c}=d^{2} / D$ is fast. When the focal spot $d=1 \mu \mathrm{m}$ (typical of focusing when using objective lens with the numerical aperture $N A>0.7$ ), in the case of sapphire with $D=1.26 \cdot 10^{-5} \mathrm{~m}^{2} / \mathrm{s}$ [ [4] (this is close to the metal temperature diffusivity), one would find $t_{\mathrm{c}} \simeq 80 \mathrm{~ns}$ which would require a laser repetition rate of at least $f=13 \mathrm{MHz}$ to keep a small focal region at the same temperature. In the case of resists and glasses, temperature diffusivity is by two orders of magnitude smaller and the laser repetition rates $f>0.5 \mathrm{MHz}$ are enough to keep constant the temperature protocol of polymerisation or waveguide writing as we demonstrated recently for fs [5] and ps [6] direct laser writing.

For a versatile fs-laser which can modify materials within a wider range of thermal properties from metals (thermal properties are close to those of diamond and sapphire) to plastics and resists, the repetition rate $f \simeq 1 \mathrm{MHz}$ can be deduced from the presented analysis. By controlling the overlapping of adjacent laser pulses the thermal conditions at the focus can be controlled within a wider parameter space. However, a too large pulse overlap is detrimental for an overall productivity which should aim at $v \simeq 1 \mathrm{~m} / \mathrm{s}$ writing speeds. When a larger focal spot is required, a smaller repetition rate can be used according to the established $f \simeq D / d^{2}$ scaling.

The pulse energy has to reach the dielectric breakdown which can be as high as $I_{\text {th }}=10 \mathrm{TW} /$ $\mathrm{cm}^{2} /$ pulse in terms of irradiance in pure dielectrics. On a $d=1 \mu \mathrm{m}$ spot this requires energy $E_{\mathrm{p}}=16 \mathrm{~nJ}$ for the pulse duration of $\tau=200 \mathrm{fs}$. Hence, only a $P_{\text {av }}=E_{\mathrm{p}} \cdot f \simeq 16 \mathrm{~mW}$ average power is required to reach the breakdown and strong absorption. For a long time a typical fs-laser oscillator had the average power $P_{\text {av }}=1 \mathrm{~W}$ at $80 \mathrm{MHz}$ which defines pulse energy $E_{\mathrm{p}}=12 \mathrm{~nJ}$, not reaching the requirements for laser machining considering light delivery losses [局. A larger pulse energy was available from fs-laser systems with regenerative amplifiers, however, they were operating at an inefficient $f=1-10 \mathrm{kHz}$ window.

The scaling of the breakdown conditions vs. the focal spot size predicts $P_{\mathrm{av}}=I_{\mathrm{th}} \tau\left(\pi \frac{d^{2}}{2}\right) \times$ $D / d^{2} \propto I_{\text {th }} \tau D$; interestingly the spot size is cancelled. This reflects the fact that a larger spot size 
requires larger pulse energy for the breakdown, but cools proportionally slower. Importantly, one can see that the average power required to drive laser breakdown is material defined: the breakdown fluence per pulse $I_{\text {th }} \tau$ and the temperature diffusion $D$. This fact is very informative and points to the importance of material properties, for which exposure conditions should be tuned accordingly - a strategy rarely adopted in practice. As an example of the material based approach we recorded densified regions prospective for waveguiding inside silica and germania glasses by exploiting peculiarities of glass transition and natural densification via control of a heat load and quenching at the focal spot [8].

The scanning speed of $1 \mathrm{~m} / \mathrm{s}$ at $f=1 \mathrm{MHz}$ gives $1 \mu \mathrm{m}$ steps and allows to have a fast micro-fabrication. Considering a tenfold increase above the dielectric breakdown as used in cutting and dicing applications, the required pulse energy has to be $E_{\mathrm{p}} \simeq 250 \mathrm{~nJ}$. For the factored in beam delivery losses (factor of 2), one would arrive at $P_{\text {av }}=0.5 \mathrm{~W}$. The high average power $>1 \mathrm{~W}$, high repetition $\sim 1 \mathrm{MHz}$, and high pulse energy $>0.25 \mu \mathrm{J}$ fs-laser systems become available recently and will mature for the industrial 24/7 operation over several years. It is noteworthy that the presented analysis can also be used to simulate conditions of ps-/ ns- or continuous $\mathrm{cw}$-laser exposure for the required thermal polymerisation, melting, welding, etc., conditions which are governed by the material properties. However, the highest fidelity is expected for the shorter laser pulses and higher repetition rate as we demonstrated in the case of $3 \mathrm{D}$ polymerisation $[6]$. The results discussed here can find a way in practical applications only when using fs-lasers which can deliver $\sim 10 \mathrm{~W}$ at $1 \mathrm{MHz}$ as an order of magnitude guide (the results shown in Figs. 1, 3, 5 are obtained using such laser source, Pharos (Light Conversion Ltd.)). (a)

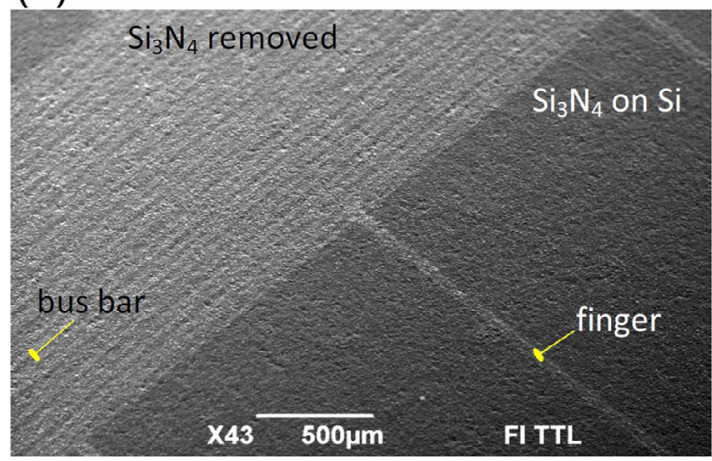

(c)

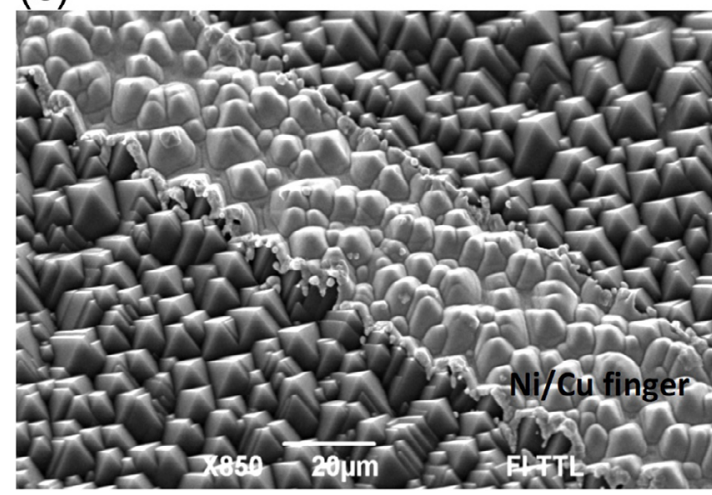

(b)

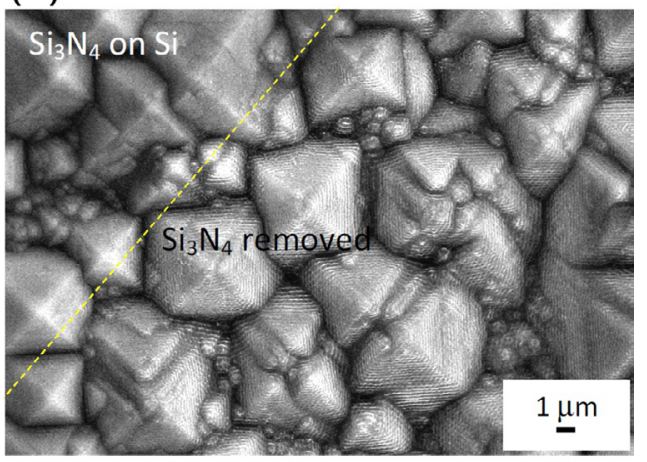

(d)

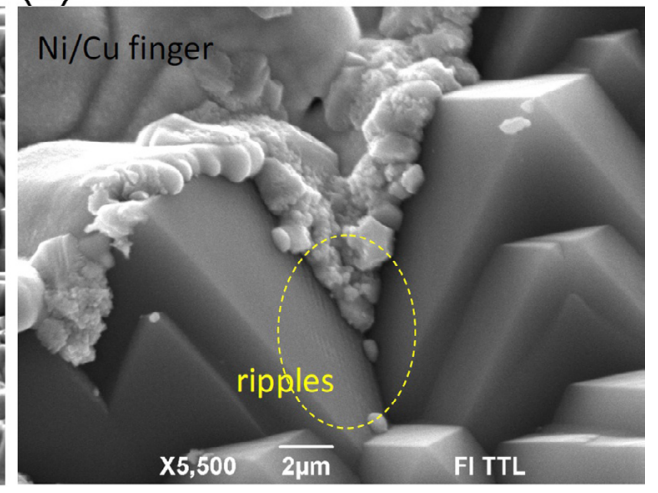

Fig. 1. (colour online) Surface patterning of crystalline-Si solar cells by $343 \mathrm{~nm} / 200 \mathrm{fs}$ pulses for removal of $\mathrm{Si}_{3} \mathrm{~N}_{4}$ antireflection coating. SEM images of (a) large and (b) zoomed-in regions of the fs-laser processed areas; note formation of ripples on the Si surface by ablation. (c, d) Fingers after metallisation at different magnification. Courtesy, Altechna Ltd. and JSC Precizika-MET SC. 


\section{Required engineering solution: beam-stage control}

By knowing what conditions we need to create at the focus (e. g. (pre-)breakdown) and maintain during fabrication in a particular material, there are further means to optimise the fabrication sequence in terms of throughput (multi-beams) or via intricate control of light-matter interaction via polarisation, angular momentum of light, pulse front tilt (or spatial chirp) [9], compensation of aberrations [10], burst exposure, mixing of colours, temporal chirp [11], spatio-temporal control, etc.

The selection of laser pulses at $\sim \mathrm{MHz}$ rates, omission of the first pulse and synchronization with coarse (air-bearing) and precise (piezo) stages operating at larger velocities and acceleration-deceleration cycles is a very demanding task. By addition of space light modulators (SLMs) and scanning galvano-mirrors (GMs) further versatility in fabrication can be explored. Namely, by multiplexing SLM multi-beam exposure with GM scanning the processing speeds can be augmented to $1-5 \mathrm{~m} / \mathrm{s}$. Also, spatio-temporal focusing and aberration compensation can be implemented. Pulse shaping using a pulse envelope control [9] can be tailored for the expected outcome via genetic algorithm optimisation when the parameter space for optimisation is large. All these trends are clearly discernable in the latest implementations of ultra-fast laser processing [12]. Also, the use of "non-diffracting" Gauss-Bessel beams in laser cutting and drilling is an emerging trend [13-15].

The added feedback tools such as an in situ monitoring, sample positioning, autofocus to keep constant height of the workpiece, and spectral characterisation all together makes a necessary set for the development of future fabrication set-ups. The very key elements are the sample positioning/handling and beam pattern generations for 3D fabrication. One cannot underestimate the importance of user friendly and intuitive graphical user interface and simple programming tools for data import and interfacing with popular drawing and CAD software. So far, this part of the set-up is usually left for the end user (typically a university lab) development. The strategy has to be abolished for the practical pilot-line applications. The results shown in Figs. 1, 3, 5 are obtained using a proprietary Altech$n a$ 's software SCA for the control of laser radiation and workpiece movement. The control software is designed to have the described architecture, functionality, and versatility. It can be considered a realization of a sub-wavelength resolution $3 \mathrm{D}$ printer for polymerisation, also a drilling, cutting, dicing, and surface texturing tool.

\section{Nano-/micro-fabrication of surface and bulk}

\subsection{Larger surface area tasks: solar cells}

The most demanding laser-structuring applications are in the field of high-efficiency silicon solar cells. Apart from edge-isolation, dicing, and marking, the fs-laser removal of antireflection coatings for the fingers and bus bars is one of the most challenging tasks. The direct laser writing could reduce significantly the number of screen-printing and wet processing steps, however the currently used ns and ps-lasers cause damage to the functional surface of solar cells.

Figure 1 shows an example the fs-laser direct write approach used to open surface regions for a wet chemical-bath metallisation. For this purpose, the third harmonics at the central wavelength $343 \mathrm{~nm}$ (the fundamental pulses are at $1030 \mathrm{~nm} / 280 \mathrm{fs}$ ) was used for a well controlled ablation of the surface area. Short wavelength pulses are absorbed only in pre-surface regions and mostly vaporise the anti-reflection/passivation $\mathrm{Si}_{3} \mathrm{~N}_{4}$ layer without apparent debris. It is noteworthy, ultrashort laser pulses make an efficient $\sim 70 \%$ nonlinear upconversion. The overall efficiency of the two-step upconversion from the fundamental to the second, and finally third harmonics was $\sim 30 \%$ ( $2 \mathrm{~W}$ out of $6 \mathrm{~W}$ at $1030 \mathrm{~nm}$ using a Pharos laser). The surface speed of the writing beam was $1 \mathrm{~m} / \mathrm{s}$ and this makes even an overall multi-scan fabrication sequence required for the bus bars time efficient. It is noteworthy that the formation of ripples on the ablated surface of a solar cell (discussed in more detail in the next Sec. 4.2) is promising for the enhanced mechanical stability of bus bars and fingers which have a considerable cross section required for large current density.

\subsection{Ripples: the surface and bulk phenomenon}

The ripples formed by fs-laser pulses via surface ablation on semi-transparent materials have a period 
$\Lambda=\left(\lambda_{0} / n\right) / 2$ defined by the light wavelength in the sub-surface regions of the refractive index $n$ for the normal incidence [16]. Surface melting, capillary waves, nonlinear absorption can slightly modify the periodicity and morphology of the ripples. The surfaces of $\mathrm{Al}_{2} \mathrm{O}_{3}$ and $\mathrm{SiC}$ substrates textured by ripples provide good light extraction surfaces in $\mathrm{GaN}$ based blue and white LEDs since a ripple period smaller than the blue $400 \mathrm{~nm}$ light can be formed on the surface of high refractive index materials $n=1.7,2.6$ for sapphire and $\mathrm{SiC}$, respectively, by fs-lasers at popular 800 and $1030 \mathrm{~nm}$ wavelengths.

The ripple pre-textured substrates can be used for the growth of light emitting multi-quantum wells and can serve as a buffer layer for the relaxation of the lattice mismatch. The fabrication of deep grooves on the sapphire substrate before the LED growth can solve a cutting and dicing step in the final LED production as we demonstrated recently [17. The annealing of laser textured regions at the typical temperatures of LED growth was found to remove surface and bulk vacancy-interstitial defects caused by fs-laser pulses [17].

\subsection{Surface: ripples for flow control}

Surface ripples can be formed on non-transparent materials. In this case, depending on the angle of incidence $\alpha$ and polarisation, two different perio- dicity structures can be formed. The accepted explanation for their formation is based on the interference of incident and surface scattered light [18]]. The normal ripples have a period $\Lambda \simeq \lambda_{0} \cos \alpha$ and run perpendicularly to the polarization, while the anomalous ripples can have smaller periodicity $\Lambda \simeq$ $\lambda_{0} / n$; however, they are usually less pronounced as they have smaller scattering efficiency [19]. Such ripple patterns are observed on metals and semiconductors when absorption is strong [20].

Ripples fabricated by $800 \mathrm{~nm} / 150$ fs laser pulses on Si substrate can be used to control surface wettability (Fig. 2). Surface tension and nano-/microstructure defines the contact angle and wetting of the surface. Rippled tracks on Si can be used as hydrophilic surface channels for micro-fluidic applications, where the speed of the water flow is controlled by the ripple direction. Ripples which are parallel to the channel drag water more than 5 times faster as compared to the ones aligned perpendicularly (Fig. 2). The control of wetting by surface texture on ablated surfaces and the influence of surface debris are revealed in a recent publication [21] and explains the superwicking effect observed earlier [22].

Another possible application of the directional water flow and control of wetting properties is in the fields of assembly and automatic alignment [23], where small parts and chips $(\sim 1 \mathrm{~mm}$ in cross section) should be handled at production line velocity. (a)

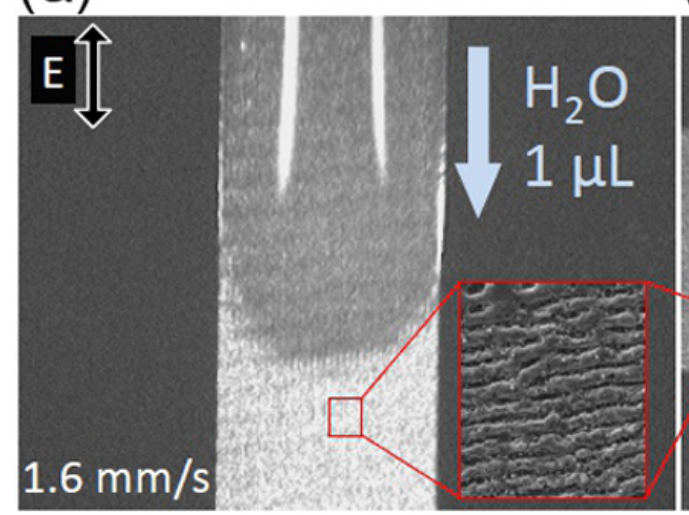

(b)

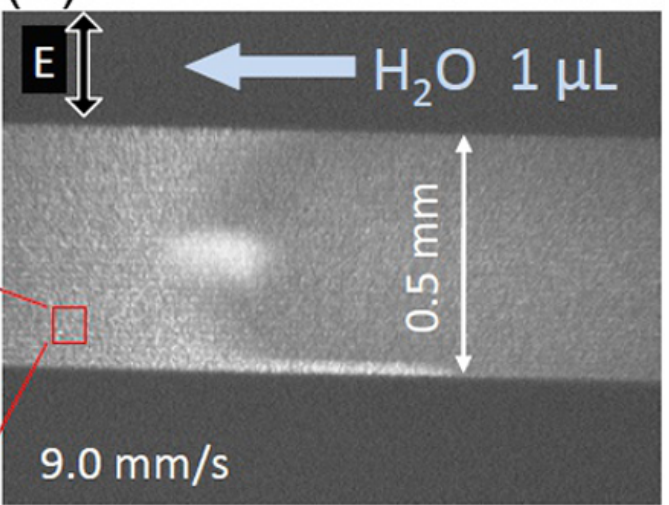

Fig. 2. (colour online) Optical microscope images of a rippled surface channel $\left(10 \times 0.5 \mathrm{~mm}^{2}\right)$ fabricated on Si using $800 \mathrm{~nm} / 150$ fs pulses: ripples aligned (a) perpendicular and (b) parallel to the channel. Inset shows a SEM image of the ripples. Laser polarisation is indicated by an arrow and is perpendicular to ripple direction. A moving water droplet (volume $1 \mu \mathrm{l}$ ) is captured in the images, arrows indicate water drag direction. For parallel ripples, water speed is around 5 times higher. 
Conventional mechanical tools are too inflexible and slow. When two small parts/chips have to be aligned onto each other, this can be accomplished by using surface pre-patterning by ripples and a water droplet. A micro-droplet is administered on the ripple textured region of the first chip and will "capture" the second chip on-the-fly. By prepatterning ripples on the two chips, the spreading of a water droplet can be controlled with the ripple pattern. Hence, the movement of a droplet and its directionality will impose momentum and orientational torque, which provide an alignment of two chips. Such tools of micro-chip handling are envisaged in future factories.

For the ripple formation on the surface (without fabrication of grooves and removal of a large amount of materials) the laser fluence is set around the threshold of material ablation $\left(0.1-0.3 \mathrm{~J} / \mathrm{cm}^{2} /\right.$ pulse), which is much lower than that used for a strong ablation and groove formation. Also, by using high a repetition rate and laser scanning, ripple patterning can be performed rather quickly on larger areas.

\subsection{Bulk: fibre drilling for sensing}

The tightly focused femtosecond laser pulses can be used for precise hole drilling and chamber formation in the optical fibre. Fig. 3(a) shows a top,

(a)

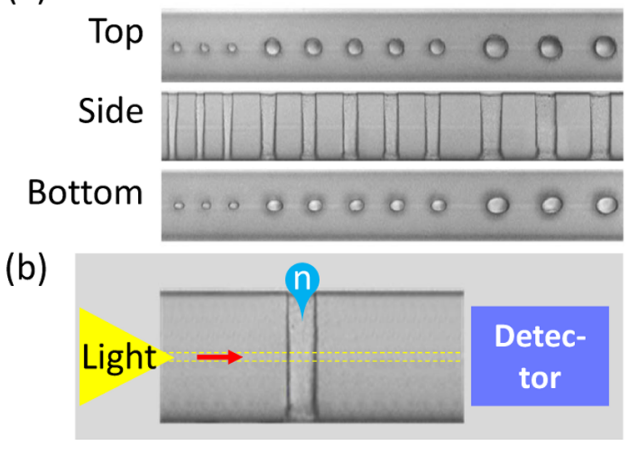

side, and bottom view of holes drilled through the single-mode $125-\mu \mathrm{m}$-thick fibre. Three different size holes are shown her from left to right: there are 3 holes of $13 \mu \mathrm{m}, 5$ holes of $20 \mu \mathrm{m}$, and 3 holes of $30 \mu \mathrm{m}$ in diameter. The drilling process is reproducible as can be judged from comparison of the same diameter holes. This fabrication task is challenging due to optical refraction, focusing and scattering effects occurring and constantly changing during the drilling process. Circular and square holes can be formed with surface roughness below $0.3 \mu \mathrm{m}$ and tapper angle below $1^{\circ}$. Through-holes comparable with a typical cell size of $10 \mu \mathrm{m}$ can be formed in a $125-\mu \mathrm{m}$-thick fibre.

We demonstrate that such fibres can be used for refractive index measurement with accuracy below $10^{-3}$ RIU (refractive index unit) in a wide range between 1.3-1.6 RIU. To show the principle of such system operation we used a single-mode fibre of $8 \mu \mathrm{m}$ core radius with a $20 \mu \mathrm{m}$ diameter hole drilled through the centre, which was filled with different refractive index $n_{f}$ liquids. Light is coupled from the LED to the fibre at one end, travels through the hole and is collected by the detector at the other end (Fig. 3(b)). Light transmission depends on the refractive index mismatch between the fibre core and liquid or gas filling the hole, and also absorption coefficient of the liquid or gas (Fig. 3(c)). Transmission dependence on a

(c)

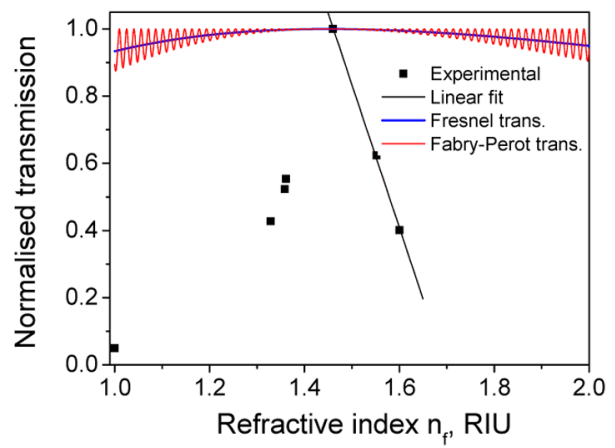

Fig. 3. (colour online) (a) Optical microscope images of different diameter holes drilled through the single mode fibre, core diameter $8 \mu \mathrm{m}$, cladding $125 \mu \mathrm{m}$. (b) Set-up for a refractive index change measurement, where white light was coupled into the fibre and transmitted light captured with a detector. (c) Transmission dependence on the refractive index of liquid filling the fibre hole. Square symbols represent experimental values, black line is a linear fit to experimental data, blue line shows theoretical transmission given by Fresnel formulas, and red line shows Fabry-Perot transmission. 
refractive index predicted by Fresnel coefficients is much smaller as compared to the experimental results. This suggests that besides reflection dependence, the scattering from the walls of the hole and coupling from one fibre end to another also depends on the refractive index mismatch between fibre core and filling liquid.

Importantly, having optically flat side walls of the fibre hole would increase the Fabry-Perot resonance effect. However, here we show that without additional antireflection coatings the smallest measurable refractive index change would be reduced (sensitivity would be increased) only outside $n_{f}=1.3-1.6$ range (see Fig. $4(\mathrm{a})$ ). For a gas sensing, refractive indexes around 1 RIU are the most important. Here, the sensitivity of refractive index change due to Fabry-Perot resonance could reach $10^{-4}$ RIU. However, unambiguous detection could only be performed in a very narrow range of refractive index values, e. g. $\sim 0.003$ RIU at $n_{f} \sim 1$ RIU (see Fig. $4(\mathrm{~b})$ ). To increase sensitivity, dielectric coatings on the hole walls should be used, which would highly improve the finesse of the Fabry-Perot cavity.

The advantage of this technique is that an a expensive LED light source for illumination and photo diode for signal collection can be used without need of complicated and expensive devices such as a spectrometer. The main application for fibres with drilled holes is expected to be in the area of gas and liquid sensing. Compact systems can be built integrating such fibre into microfluidic channels [21]. More advanced sensing techniques like surface enhanced Raman scattering (SERS) or surface enhanced fluorescence (SEF) could be considered after coating the walls of the hole by gold or silver. We have recently showed that laser fabricated ripples can give more than 10 times better SERS signals compared with commercial SERS substrates [24].

\subsection{Bulk: micro-optics and markings}

Direct 3D laser writing inside transparent materials can have applications ranging from markings against counterfeiting to decorative patterns, micro-optical elements. Figure 5 shows optical gratings recorded inside sapphire at approximately $100 \mu \mathrm{m}$ depth using $1030 \mathrm{~nm} / 280$ fs laser pulses. The absorption band at $207 \mathrm{~nm}$ corresponds to the $\mathrm{F}^{0}$ colour centre [17], an oxygen vacancy trapping two electrons, with emission at $420 \mathrm{~nm}$. On the surface, the $\mathrm{F}^{+}$centre was found due to electron emission during ablation [17]. Annealing at $\sim 1000{ }^{\circ} \mathrm{C}$ activates oxygen diffusion inside sapphire [17] and the $\mathrm{F}^{0}$ centres can be removed (as the $\mathrm{F}^{+}$centres were on the surface [17]). Even with the colour centres present, the recorded gratings are functional at the wavelengths longer than $210 \mathrm{~nm}$. The fabrication of deep-UV optical elements is usually a demanding task, which can be simplified by fs-laser writing.
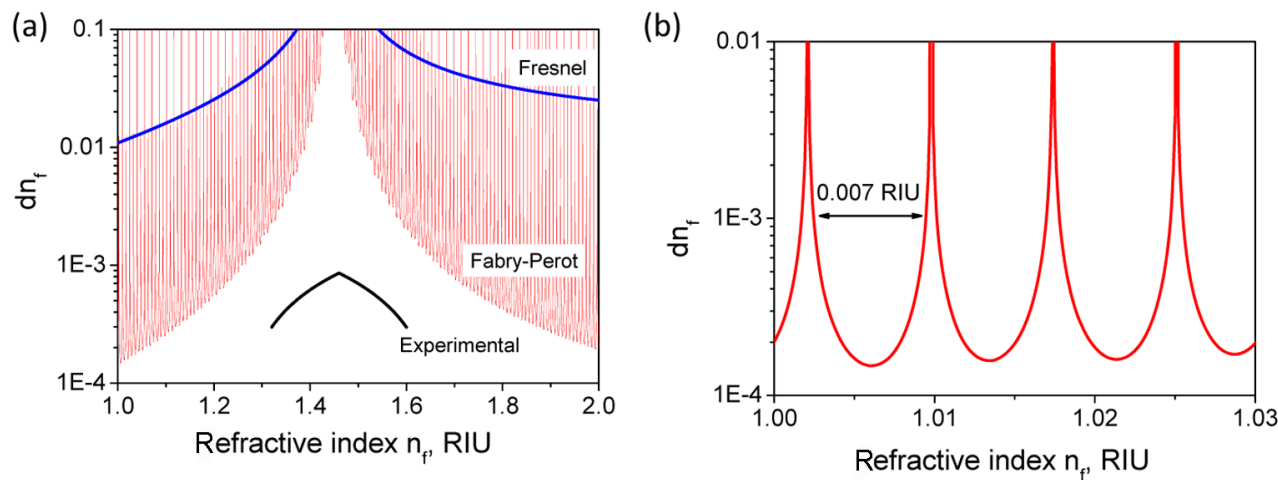

Fig. 4. (colour online) Sensitivity of the device. (a) Smallest refractive index change dependence on the refractive index of liquid or gas filling the fibre hole. Black (lower solid) line is calculated based on linear fit to experimental data, red (wiggly) and blue (upper solid) show theoretical curves predicted by Fabry-Perot and Fresnel formulas, respectively. (b) Zoomed-in part of the spectra for Fabry-Perot case. 
(a)

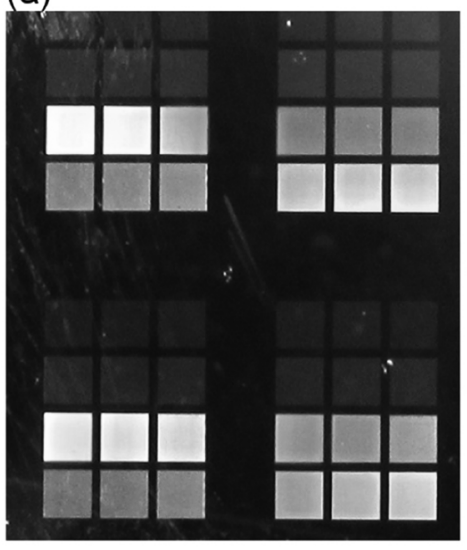

(b)

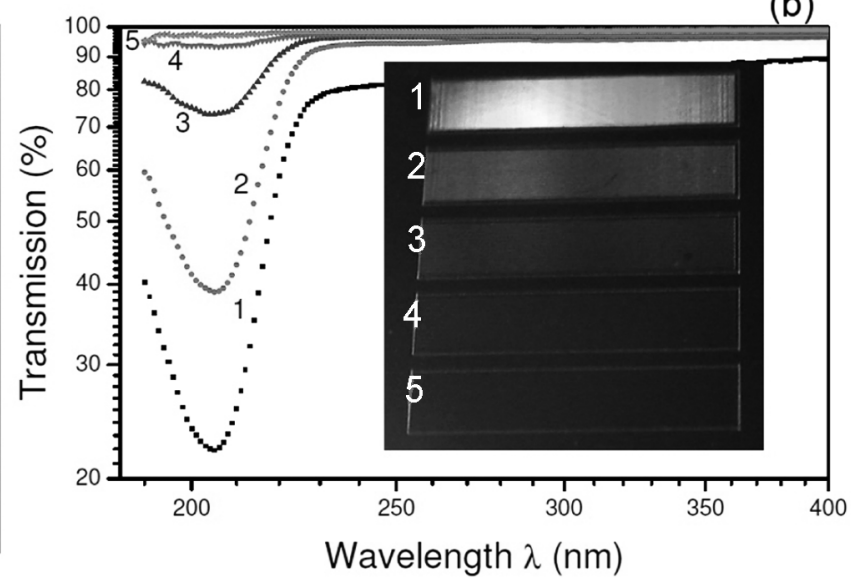

Fig. 5. (colour online) (a) Reflection photo image of line grating markings recorded inside a crystalline sapphire with pulse energy $E_{\mathrm{p}}=20 \mathrm{~nJ}$, varying in-line pulse densities (6000$10000 \mathrm{~mm}^{-1}$ ), grating line densities $\left(250\right.$ and $500 \mathrm{~mm}^{-1}$ ) and line orientations; the area of a single grating is $\sim 1 \times 1 \mathrm{~mm}^{2}$. (b) Transmission spectra of the volumetric point grids at pulse energy $E_{\mathrm{p}}=4 \mu \mathrm{J}$ and different in-line pulse densities: (1) $1000 \mathrm{~mm}^{-1}$, (2) $500 \mathrm{~mm}^{-1}$, (3) $250 \mathrm{~mm}^{-1}$, (4) $125 \mathrm{~mm}^{-1}$, (5) $62.5 \mathrm{~mm}^{-1}$. Writing pulse duration $280 \mathrm{fs}$ and wavelength $1030 \mathrm{~nm}$ were used in both cases. Courtesy, Altechna Ltd.

(a)

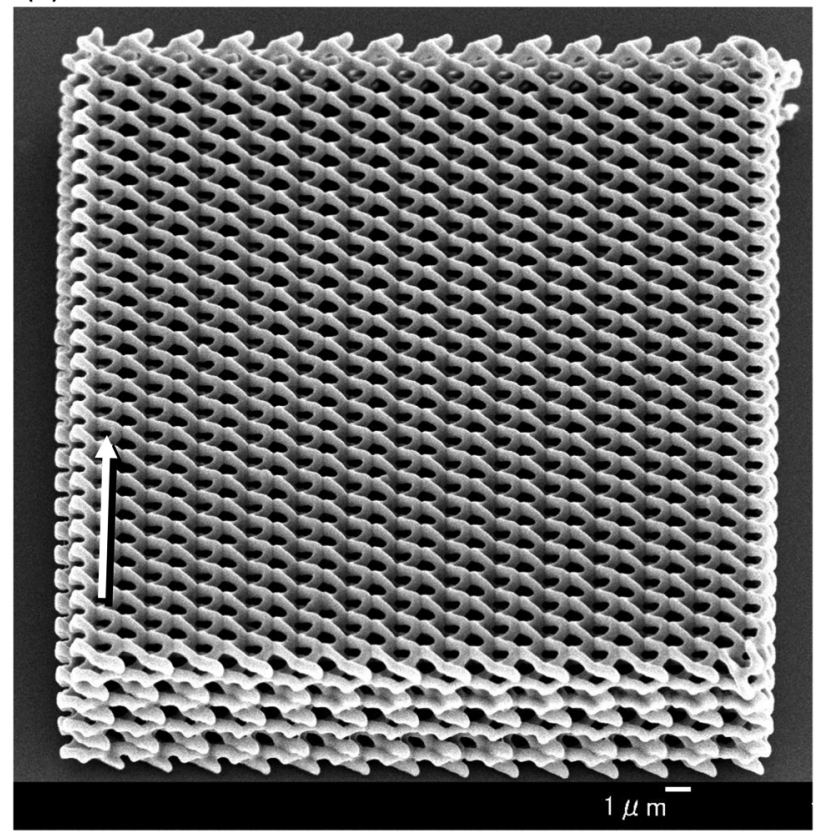

(b)

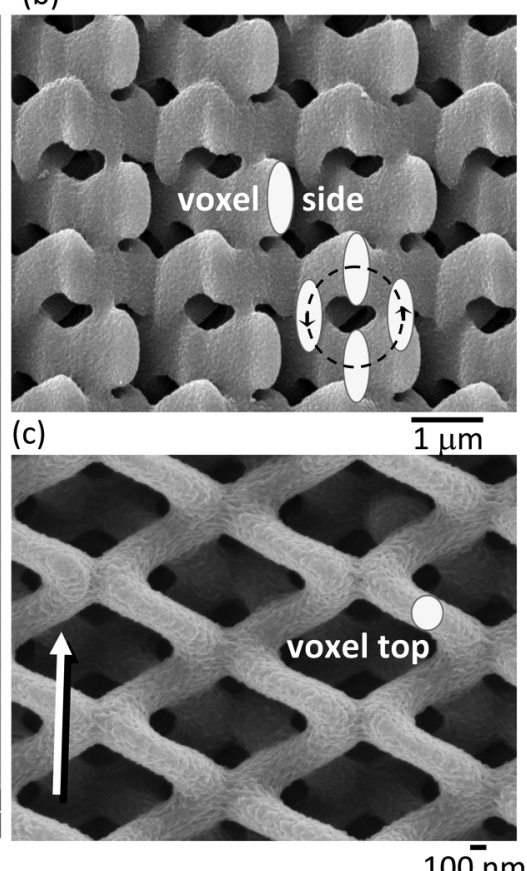

Fig. 6. (colour online) SEM images of the horizontal circular spiral photonic crystal structure [25] in SU-8 resist polymerised by direct write using $800 \mathrm{~nm} / 150 \mathrm{fs}$ pulses: (a) top slanted, (b) front, and (c) top views (note that the images are not made on the same structure). The voxel - volume element - size is schematically marked for the used focusing with an objective lens of numerical aperture $N A=1.35$; arrow in (a) and (c) runs along the direction of spiral writing. Courtesy, Dr. K.K. Seet.

It is noteworthy that material modifications with high peak intensity tightly focussed femtosecond laser pulses have opened new ways of creation of metastable phases of exotic materials with a high sub-wavelength spatial resolution that can be patterned. Amorphous and high-pressure phases of 
sapphire can be formed inside the crystalline phase [26-28] and nano-crystallites can be formed by ionic separation and thermal quenching [26, 29, 30]. Structural modifications at the irradiated locations can be used to record patterns of birefringence [4], control heat transport [31], and alter optically linear and nonlinear properties as demonstrated in lithium niobate [32-34].

\subsection{Bulk: $3 D$ polymerisation}

Figure 6 shows an example of direct laser polymerisation of a photonic crystal. Such structures have different spectral transmission/reflection for the leftand right-hand circularly polarised light. Moreover, an asymmetry of the focal spot size in axial (vertical in (b)) and lateral (horizontal in (b)) directions introduces additional form birefringence. There are no other means to freely fabricate such structures other than direct laser write. 3D laser polymerisation with $200-250 \mathrm{~nm}$ resolution is a routine task achievable without super-critical point drying and can be used for photonic applications [35-40]. Resolution down to $20 \mathrm{~nm}$ (corresponding to $\lambda / 40$ ) in $3 \mathrm{D}$ on single structures is available since 2005 [41]. Polymerised 3D templates can be used for chemical inversion into glass and semiconductor hosts or as micro-mechanical scaffolds [42, 40].

It has been demonstrated that direct laser curing of polymers is an efficient method to fabricate such 3D structures [43] and it does not rely on resonant two-photon absorption [5, 6, 44]. Thermal curing of photo-polymers benefits from the high repetition rate and has been used to fabricate complex micro-optical elements: fibre-tip micro-lenses, micro-optical vortex generators [45], hybrid (diffractive-refractive) micro-optics [46], and light collimators [47]. Complex 3D structures can be polymerised and used in micro-fluid channels 48 .

\section{Conclusions}

We demonstrated unique features of fs-laser processing where competing technologies cannot deliver comparable quality, namely well-controlled removal of films of tens-of-nm thickness with minimum damage to solar cell surface. Drilling through-holes in the most demanding landscapes (fibres) with a few micrometer scale precision and high fidelity of surface control can be achieved by high-precision control of laser radiation and sample movement. The formation of ripples inside transparent materials, on their surfaces, and on the absorbing surfaces of metals and semiconductors is expected to find new applications in micro-fluidics, self-assembly of micro-chips, tribology, and sensing.

Free space 3D laser writing of photonic crystal structures of arbitrary patterns and micro-optical elements with high resolution is already an established technology and demonstrates versatility of a $3 \mathrm{D}$ printer with sub-wavelength resolution. All these demonstrations can make transition from the in-the-lab achievement to the pilot line production in coming years due to fast progress in availability of affordable and reliable ultra-fast femtosecond high pulse energy and high average power lasers.

\section{Acknowledgements}

We acknowledge partial support by the Australian Research Council DP120102980 grant. S. J. is grateful to Prof. Eugene G. Gamaly and Prof. Andrei V. Rode for discussions of various aspects of lightmatter interaction, also acknowledges support via VP1-3.1-ŠMM-01-V-02-001 funding scheme. We acknowledge a discussion with Dr. Filip Granek on ripples in solar cell applications.

\section{References}

-1] E. Gamaly, Femtosecond Laser-Matter Interactions: Theory, Experiments, and Applications (Pan Stanford Publishing, Singapore, 2011).

[2] Three-dimensional Laser Microfabrication: Fundamentals and Applications, eds. H. Misawa and S. Juodkazis (Wiley, Weinheim, 2006).

[3] L. Hallo, C. Mézel, A. Bourgeade, D. Hébert, E.G. Gamaly, and S. Juodkazis, Laser-matter interaction in transparent materials: confined microexplosion and jet formation, in: NATO Science for Peace and Security Series B: Physics and Biophysics (Springer, Netherlands, 2009) pp. 121-146.

[4] J. Morikawa, A. Orie, T. Hashimoto, and S. Juodkazis, Thermal and optical properties of the femtosecond-laser-structured and stress-induced birefringent regions of sapphire, Opt. Express 18(8), 8300-8310 (2010).

[5] M. Malinauskas, A. Žukauskas, G. Bičkauskaitè, R. Gadonas, and S. Juodkazis, Mechanisms of three-dimensional structuring of photo-polymers by tightly focussed femtosecond laser pulses, Opt. Express 18(10), 10209-10221 (2010).

[6] M. Malinauskas, P. Danilevičius, and S. Juodkazis, Three-dimensional micro-/nano-structuring via 
direct write polymerization with picosecond laser pulses, Opt. Express 19(6), 5602-5610 (2011).

[7] E. Vanagas, I. Kudryashov, D. Tuzhilin, S. Juodkazis, S. Matsuo, and H. Misawa, Surface nanostructuring of borosilicate glass by femtosecond $\mathrm{nJ}$ energy pulses, Appl. Phys. Lett. 82(17), 2901-2903 (2003).

[8] L. Bressel, D. de Ligny, C. Sonneville, V. MartinezAndrieux, V. Mizeikis, R. Buividas, and S. Juodkazis, Femtosecond laser induced density changes in $\mathrm{GeO}_{2}$ and $\mathrm{SiO}_{2}$ glasses: fictive temperature effect, Opt. Mater. Express 1, 605-613 (2011).

[9] S. Juodkazis, K. Nishimura, and H. Misawa, Threedimensional laser structuring of materials at tight focusing, Chin. Opt. Lett. 5, S198-S200 (2007).

[10] A. Marcinkevicius, V. Mizeikis, S. Juodkazis, S. Matsuo, and H. Misawa, Effect of refractive index-mismatch on laser microfabrication in silica glass, Appl. Phys. A 76, 257-260 (2003).

[11] K. Hatanaka, T. Ida, H. Ono, S.-I. Matsushima, H. Fukumura, S. Juodkazis, and H. Misawa, Chirp effect in hard X-ray generation from liquid target when irradiated by femtosecond pulses, Opt. Express 16(17), 12650-12657 (2008).

[12]S. Juodkazis, V. Mizeikis, and H. Misawa, Threedimensional microfabrication of materials by femtosecond lasers for photonics applications, J. Appl. Phys. 106(5), 051101 (2009).

[13] A. Marcinkevicius, S. Juodkazis, S. Matsuo, V. Mizeikis, and H. Misawa, Application of Bessel beams for microfabrication of dielectrics by femtosecond laser, Jpn. J. Appl. Phys. A 40(11), L1197L1199 (2001).

[14] S. Juodkazis, V. Mizeikis, S. Matsuo, K. Ueno, and H. Misawa, Three-dimensional micro- and nanostructuring of materials by tightly focused laser radiation, Bull. Chem. Soc. Jpn. 81(4), 411-448 (2008).

[15] M. Duocastella and C.B. Arnold, Bessel and annular beams for materials processing, Laser Photonics Rev. 6(5), 607 (2012) pp. 1-15; http://dx.doi.org/10.1002/lpor.201100031.

[16] R. Buividas, L. Rosa, R. Šliupas, T. Kudrius, G. Šlekys, V. Datsyuk, and S. Juodkazis, Mechanism of fine ripple formation on surfaces of (semi)transparent materials via a half-wavelength cavity feedback, Nanotechn. 22, 055304 (2011).

[17]T. Kudrius, G. Šlekys, and S. Juodkazis, Surfacetexturing of sapphire by femtosecond laser pulses for photonic applications, J. Phys. D 43(14), 145501 (2010).

[18] J. Sipe, J. Young, J. Preston, and H. Van Driel, Laser-induced periodic surface structure. I. Theory, Phys. Rev. B 27(2), 1141 (1983).

[19]S. Juodkazis, N. Kujime, H. Okuno, V. Mizeikis, S. Matsuo, and H. Misawa, Towards nanostructuring of materials by ripples, in: CREST and QNN'03 Joint Int. Workshop (Hyogo, Japan, 21-23 July 2003) pp. 117-121.
[20] H. Iwase, S. Kokubo, S. Juodkazis, and H. Misawa, Suppression of ripples on Ni surface via a polarization grating, Opt. Express 17(6), 4388-4396 (2009).

[21] R. Buividas, M. Mikutis, G. Gervinskas, D. Day, G. Slekys, and S. Juodkazis, Femtosecond laser drilling of optical fibres for sensing in microfluidic applications, Proc. SPIE (2012) [in press].

[22] A.Y. Vorobyev and C. Guo, Laser turns silicon superwicking, Opt. Express 18(7), 6455-6460 (2010).

[23] G.-W. Römer, M. Jorritsma, D. Arnaldo del Cerro, B. Chang, V. Liimatainen, Q. Zhou, and B. Huis in 't Veld, Laser micro-machining of hydrophobic-hydrophilic patterns for fluid driven selfalignment in micro-assembly, in: Proceedings of LPM2011 - the 12th International Symposium on Laser Precision Microfabrication, 2011.

[24] R. Buividas, P. Stoddart, and S. Juodkazis, Laser fabricated ripple substrates for surface-enhanced Raman scattering, Ann. Phys. 524(11), L5-L10 (2012).

[25] K.K. Seet, V. Mizeikis, S. Juodkazis, and H. Misawa, Three-dimensional horizontal circular spirals photonic crystals with stop gaps below $1 \mu \mathrm{m}$, Appl. Phys. Lett. 88(22), 221101 (2006).

[26] A. Vailionis, E.G. Gamaly, V. Mizeikis, W. Yang, A. Rode, and S. Juodkazis, Evidence of superdense Aluminum synthesized by ultra-fast microexplosion, Nature Commun. 2, 445 (2011).

[27] S. Juodkazis, H. Misawa, E.G. Gamaly, B. LutherDavis, L. Hallo, P. Nicolai, and V. Tikhonchuk, Is the nano-explosion really microscopic?, J. NonCryst. Solids 355(18-21), 1160-1162 (2009).

[28] M. Mazilu, S. Juodkazis, T. Ebisui, and H. Misawa, Structural characterization of shock-affected sapphire, Appl. Phys. A 86(2), 197-200 (2007).

[29] S. Juodkazis, S. Kohara, Y. Ohishi, N. Hirao, A. Vailionis, V. Mizeikis, A. Saito, and A. Rode, Structural changes in femtosecond laser modified regions inside fused silica, J. Opt. 12(12), 124007 (2010).

[30] V. Mizeikis, S. Kohara, Y. Onishi, N. Hirao, A. Saito, A. Vailionis, and S. Juodkazis, Synthesis of high-pressure phases of silica by laser-induced optical breakdown, Appl. Phys. A 104(3), 903-906 (2011).

[31]J. Morikawa, E. Hayakawa, T. Hashimoto, R. Buividas, and S. Juodkazis, Thermal imaging of a heat transport in regions structured by femtosecond laser, Opt. Express 19(21), 20542-20550 (2011).

[32] S. Juodkazis, M. Sudzius, V. Mizeikis, H. Misawa, E.G. Gamaly, Y. Liu, O.A. Louchev, and K. Kitamura, Three-dimensional recording by tightly focused femtosecond pulses in $\mathrm{LiNbO}_{3}$, Appl. Phys. Lett. 89, 062903 (2006).

[33]E. Gamaly, S. Juodkazis, V. Mizeikis, H. Misawa, A. Rode, and W. Krolokowski, Modification of refractive index by a single fs-pulse confined inside 
a bulk of a photo-refractive crystal, Phys. Rev. B 81(5), 054113 (2010).

[34] S. Juodkazis, V. Mizeikis, M. Sudžius, H. Misawa, K. Kitamura, S. Takekawa, E.G. Gamaly, W.Z. Krolikowski, and A.V. Rode, Laser induced memory bits in photorefractive $\mathrm{LiNbO}_{3}$ and $\mathrm{LiTaO}_{3}$, Appl. Phys. A 93(1), 129-133 (2008).

[35] V. Mizeikis, H.-B. Sun, A. Marcinkevicius, J. Nishii, S. Juodkazis, S. Matsuo, and H. Misawa, Femtosecond laser micro-fabrication for tailoring photonic crystals in resins and silica, J. Photochem. Photobiol. A 145(1-2), 41-47 (2001).

[36] V. Mizeikis, K.K. Seet, S. Juodkazis, and H. Misawa, Three-dimensional woodpile photonic crystal templates for infrared spectral range, Opt. Lett. 29(17), 2061-2063 (2004).

[37] K.K. Seet, V. Mizeikis, S. Matsuo, S. Juodkazis, and $\mathrm{H}$. Misawa, Three-dimensional spiral-architecture photonic crystals obtained by direct laser writing, Adv. Mater. 17(5), 541-545 (2005).

[38] K.K. Seet, V. Mizeikis, S. Juodkazis, and H. Misawa, Spiral three-dimensional photonic crystals for telecomunications spectral range, Appl. Phys. A 82(4), 683-688 (2005).

[39] K.K. Seet, V. Mizeikis, S. Juodkazis, and H. Misawa, Three-dimentional circular spiral potonic crystal structures recorded by femtosecond pulses, J. Non-Cryst. Solids 352(23-25), 2390-2394 (2006).

[40]S. Juodkazis, V. Mizeikis, K.K. Seet, H. Misawa, and U.G.K. Wegst, Mechanical properties and tuning of three-dimensional polymeric photonic crystals, Appl. Phys. Lett. 91(24), 241904 (2007).

[41]S. Juodkazis, V. Mizeikis, K.K. Seet, M. Miwa, and H. Misawa, Two-photon lithography of nanorods in SU-8 photoresist, Nanotechnol. 16, 846-849 (2005).
[42] K.K. Seet, V. Mizeikis, K. Kannari, S. Juodkazis, H. Misawa, N. Tetreault, and S. John, Templating and replication of spiral photonic crystals for silicon photonics, IEEE J. Sel. Top. Quant. Electr. 14(4), 1064-1073 (2008).

[43] K.K. Seet, S. Juodkazis, V. Jarutis, and H. Misawa, Feature-size reduction of photopolymerized structures by femtosecond optical curing of SU-8, Appl. Phys. Lett. 89, 024106 (2006).

[44] M. Malinauskas, E. Brasselet, and S. Juodkazis, Fine structuring of integrated micro-optical components using lasers, SPIE Newsroom (2011); http://dx.doi.org/10.1117/2.1201107.003708.

[45]E. Brasselet, M. Malinauskas, A. Žukauskas, and S. Juodkazis, Photo-polymerized microscopic vortex beam generators: precise delivery of optical orbital angular momentum, Appl. Phys. Lett. 97, 211108 (2010).

[46]M. Malinauskas, H. Gilbergs, A. Žukauskas, K. Belazaras, V. Purlys, M. Rutkauskas, G. Bičkauskaite, D. Paipulas, R. Gadonas, A. Piskarskas, M. Farsari, and S. Juodkazis, Femtosecond laser polymerization of hybrid/integrated micro-optical elements and their characterization, J. Opt. 12(12), 124010 (2010).

[47]J. Trull, L. Maigyte, V. Mizeikis, M. Malinauskas, S. Juodkazis, C. Cojocaru, M. Rutkauskas, M. Peckus, V. Sirutkaitis, and K. Staliunas, Formation of collimated beams by woodpile photonic crystal, Phys. Rev. B 84, 033812 (2011).

[48] Q. Sun, S. Juodkazis, N. Murazawa, V. Mizeikis, and H. Misawa, Freestanding and movable photonic microstructures fabricated by photopolymerization with femtosecond laser pulses, J. Micromech. Microeng. 20, 035004 (2010).

\title{
APDIRBIMAS FEMTOSEKUNDINIU LAZERIU - NAUJA PERSPEKTYVI TECHNOLOGIJA
}

\author{
R. Buividas s, ${ }^{\text {a, }}$, M. Mikutis ${ }^{c, d}$, T. Kudrius ${ }^{c, d}$, A. Greičius s ${ }^{c}$, G. Šlekys ${ }^{c}$, S. Juodkazis a,b \\ a Svinberno technologijos universitetas, Hawthorn, Australija \\ ${ }^{\mathrm{b}}$ Melburno nanotechnologijos centras, Clayton, Australija \\ " UAB „Altechna“, Vilnius, Lietuva \\ ${ }^{\mathrm{d}}$ Vilniaus universiteto Lazeriniu tyrimu centras, Vilnius, Lietuva
}

\section{Santrauka}

Pristatomi didelio tikslumo paviršiaus abliacijos, paviršinių sluoksnių pašalinimo ir raibulių formavimo rezultatai. Aptariamas tūrinis puslaidininkinių ir dielektrinių medžiagų apdirbimas polimerizacijos, ženklinimo, pjovimo ir gręžimo būdais.

Nagrinèti procesai, tinkami didelio našumo pramoninèms užduotims atlikti ir suteikti naujų savybių, kurių neįmanoma igyvendinti kitomis šiuolaikinèmis konkuruojančiomis technologijomis. Aptariamos unikalios tiesioginio lazerinio fabrikavimo femtosekundiniais lazerio impulsais savybès. Pateikiamos inžineriniu uždavinių sprendimų metodikos. Lazerinès spinduliuotès parametrai yra parenkami atsižvelgiant ị apdorojimo sąlygas, reikalingas konkrečiai medžiagai ar gaminiui. 